\title{
INDOXYL ACETATE ESTERASE IN MITOCHONDRIA
}

\author{
TAKao KAWASHIMA and Fumio MURATA \\ Department of Surgery, Okayama University Medical School, Okayama
}

Received for Publication December 5, 1969

\begin{abstract}
Mitochondrial activity of the indoxyl acetate esterase was proved in absorptive cells of rat jejunum and in parenchymal cells of rat liver by an indoxyl acetate esterase stain. And continuities between the endoplasmic reticulum and the mitochondria were observed by chance in these cells.
\end{abstract}

Indoxyl acetate esterase is demonstrable in endoplasmic reticulum, nuclear envelopes and lysosomes in the proximal segment cells of rat kidney cortex, but not in mitochondria (7). In rat liver cells and jejunal absorptive cells, however, it is positive in mitochondria as well as in endoplasmic reticulum, nuclear envelopes and some others (8). In addition, assuming that the esterase activity is present in the mitochondria and the other organelles, a morphological communication of these organelles was suspected and observed in electron microscope.

\section{MATERIALS AND METHODS}

Several pieces of rat liver and upper part of jejunum were excised from albino rats under a slight anesthesia with ether. These were immediately fixed in a $4 \%$ formaldehyde solution containing $0.05 \mathrm{M}$ phosphate buffer and $5 \%$ sucrose at $4^{\circ} \mathrm{C}$ for an hour. The fixed tissues were rinsed in a chilled $0.85 \%$ sodium chloride solution for $15 \mathrm{~min}$ and stored in the same kind of solution at $4^{\circ} \mathrm{C}$ overnight. These tissues then were cut $20 \mu$ thick in a criostat, stained in a medium reported previously $(7,9)$ at room temperature for $15 \mathrm{~min}$, washed in a $0.85 \%$ sodium chloride solution with 3 changes for an hour, and osmicated in a $2.0 \%$ osmium tetroxide solution. The osmicated tissues were washed, dehydrated, embedded in epon plastic by a routine method for electron microscopy.

Two controls were carried out by the same procedure as mentioned above except indoxyl acetate was omitted in a control and $10^{-3} M$ sodium fluoride was added in another respectively.

\section{RESULTS}

Absorptive cells of the jejunum: The plasma membrane covering the microvilli showed a trace of the esterase activity and the plasma membrane of the lateral cellular border and the bases of the microvilli revealed slight to moderate activities. The activity in the mitochondrial envelopes in the absorptive cells was so strong that the outer and the inner layers were not able to discriminate, and the limiting membrane of the crista revealed weak to moderate activities. Continuities between the envelopes and the endoplasmic reticulum were observed by chance (arrows in Fig. 1). The limiting membrane of the small vesicles which are considered as the smooth surfaced endoplasmic reticulum were moderately reactive 


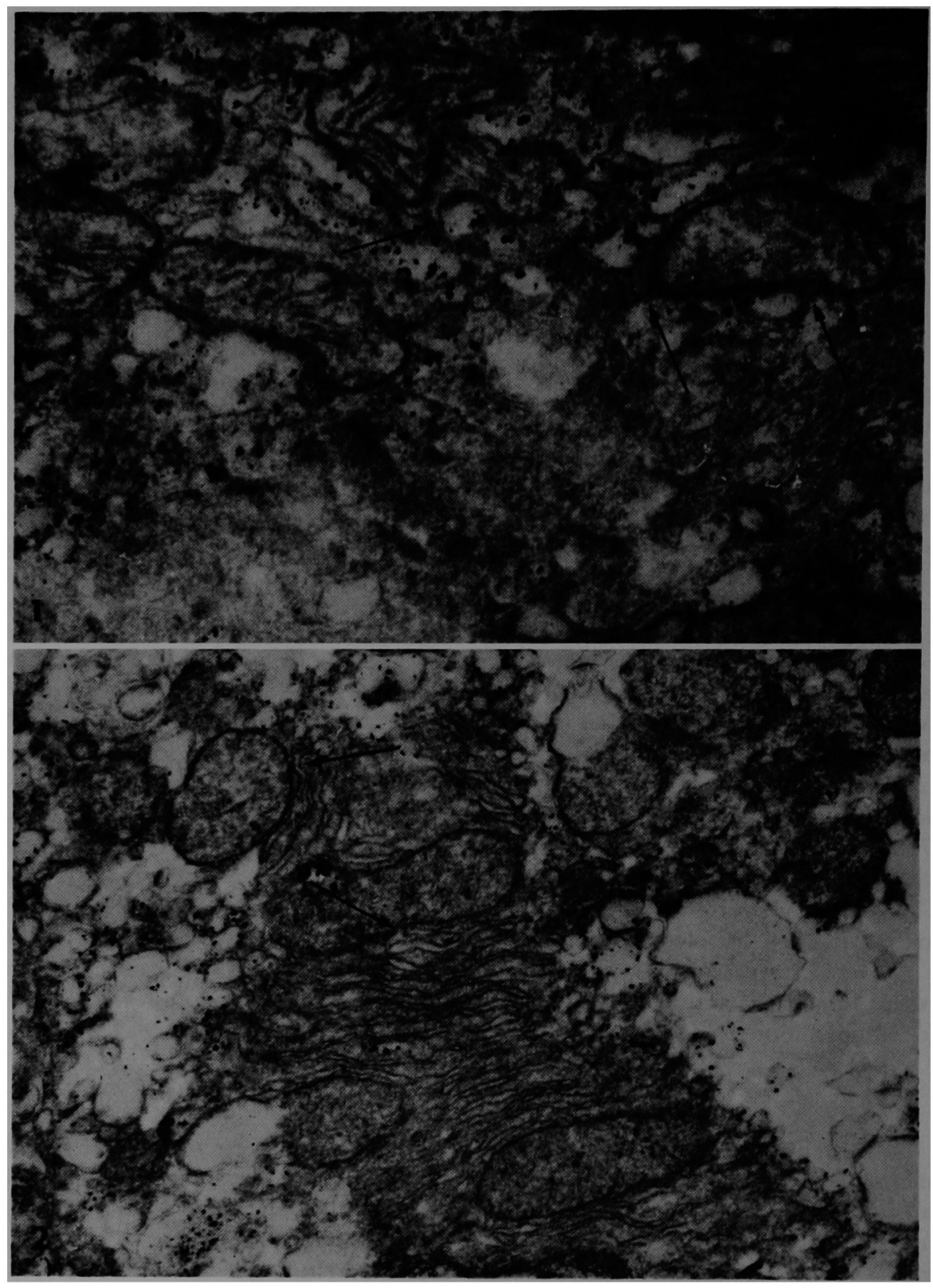


for the esterase and also the membranes of the rough surfaced endoplasmic reticulum were moderately reactive. In the nuclear envelopes a strong reaction of the esterase was observed but the outer and inner layers were hardly distinguishable. The multivesicular bodies showed a moderate activity in the bordering membrane and in some of the vesicles inside. A probable membranous activity in the Goldi complex was checked.

Parenchymal cells of the liver: The plasma membrane except that of the microvilli projecting into the bile canaliculi and into the space of Disse showed weak to moderate activities of the esterase. The envelope of the mitochondria had a strong activity but it was not clearly distinguishable whether the activity was localized on the outer or inner limiting membranes which rarely had anastomoses to the adjacent endoplasmic reticulum (arrows in Fig. 2). The crista of the mitochondria also presented a weak membranous activity. On the limiting membranes of the smooth and rough surfaced endoplasmic reticulum and of the small vacuoles and vesicles, a moderate reaction was usually demonstrated. The most intense reaction was localized in the nuclear envelopes, and the microbodies moderately presented a diffuse non-membranous stain. About the Goldi complex the activity has not been confirmed yet.

\section{DISCUSSION}

Since mitochondrial activity of esterase was shown by Barrnett and Hangstrom using thiolacetate and thiobutyrate in 1963 (1), it has been demonstrated in mitochondria in intestinal absorptive cells, hepatic cells and sebaceous gland epithelial cells by Bell and Barrnett with thiocarboxylic acids as substrate (2) and proved in intestinal absorptive cells, hepatic cells, presynaptic axon and striated muscle by Kawashima et al. using indoxyl acetate as substrate (8). The mitochondria in these cells presumably can play a role of hydrolysis for indoxyl acetate or thiol-substituted carboxylic acids as the case of the other esterase-active organelles shown in our study and in the report of Bell and Barrnett (2). The enzymatic relationship between endoplasmic reticulum and mitochondria lent an assumption of a certain morphological communication of the mitochondrial envelope with the endoplasmic reticulum in the jejunal absorptive cells and the hepatic cells like anastomoses between endoplasmic reticulum and nuclear envelope and between endoplasmic reticulum and lysosomes $(7,6)$ and those of mitochondrial membrane with the nuclear membrane or the Golgi complex $(3,4,5)$. The present result clearly tells such continuities between the endoplasmic reticulum and the mitochondria, that is probably concerned with the distribution of the indoxyl acetate esterase. At least it can be suspected that all of sites of the indoxyl acetate esterase connect with certain membranous structures. Morphological variations of the mitochondria in size and shape have been observed by many investigators depending on the functional stage of the cells such as different stages of nutritions. These chages might be due to the

Fig. 1. An absorptive cell of rat jejunum stained with indoxyl acetate as substrate. $\quad \times 60,000$ Fig. 2. An parenchymal cell of rat liver stained with indoxyl acetate. $\quad \times 22,000$

The azoindoxyl osmium polymer is visible on the membrane structures as mentioned in the present results. An osmium artifact is seen as copious small precipitations.

Arrows show the continuities of the mitochondrial membranes with the endoplasmic reticulum. 
transportation of certain stuffs through the continuities of the mitochondrial membrane with the endoplasmic reticulum in the jejunal absorptive cells and the liver cells as well as due to the penetration through the mitochondrial envelope:

\section{ACKNOWLEDGEMENTS}

We wish to acknowledge Prof. A. M. Seligman and Dr. R. E. Plapinger for the courtesy of BAXD. We also thank Prof. S. Tanaka and Dr. T. Ogata for kind guidance throughout this work.

\section{REFERENCES}

1. Barrnett, R. J. and Hangstrom, P.: Histochemical and fine structural study of lipid degradation and synthesis in muscle of fasting rats. J. Cell Biol. 19; 5A, 1963.

2. Bell, M. and Barrnett, R. J.: The use of thiol-substituted carboxylic acids as histochemical substrates. J. Histochem. Cytochem. 13; 611, 1965.

3. Brandt, P. W. and Pappas, G. D.: Mitochondria. J. Biophysic. and Biochem. Cytol. 6; 91, 1959

4. Dempsey, E.: Variations in the structure of mitochondria, J. Biophysic. and Biochem. Cytol. 2 ; suppl. 305, 1956.

5. Hoffman, H. and Grigg, G. W.: An electron microscopic study of mitochondria formation. Exp. Cell Res. 15; 118, 1958.

6. Hugon, J. S. and Borgers, M.: Fine structural localization of three lysosomal enzymes and nonspecific alkaline phosphatase in the villus of the human duodenum. Gastroenterolog $y 55 ; 608$, 1968.

7. Kawashima, T.: A cytochemical method for indoxyl acetate esterase. Acta Histochem. Cytochem. $1 ; 147,1968$.

8. Kawashima, T., Murata, F. and Ogata, T.: Some problems on an indoxyl acetate esterase reaction coupled by tetrazotized BAXD. The 10th congress of Japan Society of Histochem. and Cytochem., 1969.

9. Kawashima. T, and Murata, F.: Electron microscopic demonstraton of cholinesterase in the human intercostal muscle by an indoxyl acetate esterase method. Acta Histochem. Cytochem. 2; 54,1969 